\title{
Isolation and identification of bovine primary hepatocytes
}

\author{
Q.D. Jiang ${ }^{1}$, H.P. Li² ${ }^{2}$ F.J. Liu², X.J. Wang ${ }^{2}$, Y.J. Guo², L.F. Wang ${ }^{2}$, \\ W.F. Lu' ${ }^{2}$, H.J. Li' ${ }^{2}$ X.P. Li ${ }^{1}$ and G.Y. Yang ${ }^{2}$ \\ ${ }^{1}$ College of Veterinary Medicine, Northwest A\&F University, Yangling, \\ Shanxi, China \\ ${ }^{2}$ Key Laboratory of Animal Biochemistry and Nutrition, Ministry of Agriculture, \\ Henan Agricultural University, Zhengzhou, Henan, China \\ Corresponding authors: X.P. Li / G.Y. Yang \\ E-mail: jiangqd2000@126.com
}

Genet. Mol. Res. 12 (4): 5186-5194 (2013)

Received February 25, 2013

Accepted July 8, 2013

Published October 30, 2013

DOI http://dx.doi.org/10.4238/2013.October.30.3

\begin{abstract}
The liver is a unique organ that is endowed with a plethora of specialized functions. Most of its functional traits are controlled by hepatocytes. Primary hepatocytes have been used widely in in vitro models to understand the biological processes occurring in the liver. There are a number of methods used to separate hepatocytes, but the cell activity and purity are much lower in this condition. On the basis of previous research, in this study, the two-step collagenase perfusion technique was used for isolating hepatocytes. The key proteins of hepatocytes, cytokeratin-18 (CK-18) and albumin (ALB), were used to identify cells, and their contents were evaluated by immunohistochemistry and Western blotting. The results showed that the isolated hepatocytes comprised more than $96 \%$ of the corresponding protein volume stability. Therefore, this method was demonstrated to be reliable for identifying hepatocytes.
\end{abstract}

Key words: Bovine; Primary hepatocyte; Isolation; Identification; Culture 


\section{INTRODUCTION}

The liver is a unique organ with a plethora of specialized functions that are mostly controlled by hepatocytes. Primary hepatocytes have been used as in vitro models to understand the biological processes occurring in the liver. Freshly isolated hepatocytes retain their liver-specific functions and minimize the amount of components required for evaluating hepatotoxicity (Shen et al., 2006). In vitro systems with primary hepatocytes are frequently applied for 1) prediction of in vivo metabolism of test substances, 2) identification of hepatotoxic and/or genotoxic substances, and 3) identification of substances that cause enzyme induction or inhibition (Hengstler et al., 1999, 2003; Osterod et al., 2002; Ringel et al., 2002). Strong correlations have been observed between data obtained in vitro using hepatocytes and in vivo observations (Li et al., 1999; Hengstler et al., 2000a,b). In order to conduct an efficient in vitro analysis, hepatocyte isolates must be completely established. Although some methods for the isolation and identification of hepatocytes have been proposed to date (Crosby et al., 2001; Azuma et al., 2003; Bordoni et al., 2004; Tsuchiya et al., 2005), the purity, activity, and yield of these isolated hepatocytes are relatively low, and its mRNA integrity is much poorer (Nagaki et al., 2001; Morsiani et al., 2002). In order to further improve upon and solve these problems, in this study, the two-step collagenase perfusion technique was used to isolate hepatocytes on the basis of previous research. The two-step collagenase perfusion technique is the most commonly used procedure to isolate hepatocytes from the livers of animals. This method is based on numerous isolation techniques, such as collagenase perfusion of the liver (Puviani et al., 1998; Guguen-Guillouzo, 2002; Li et al., 2005; Park and Song, 2006), permeation of the liver with chelator solutions (Battle and Stacey, 2001; Kravchenko et al., 2002), and enzymatic digestion or mechanical dissociation of the liver parenchyma (Puviani et al., 1998). When the cell yield is low or selective removal of the non-parenchymal cells is needed, Percoll (Puviani et al., 1998) or Ficoll (Guguen-Guillouzo, 2002) solutions may be used for the purification of cells. One of the fundamental principles of this procedure is based on the notion that $\mathrm{Ca}^{2+}$ ions play a pivotal role in cellular adhesion. Initially, the freshly isolated liver is perfused with a $\mathrm{Ca}^{2+}$-free medium, which is often supplemented with a $\mathrm{Ca}^{2+}$ chelator (e.g., ethylenediamine tetraacetic acid), in order to disrupt $\mathrm{Ca}^{2+}$-dependent (cadherinbased) cell junctions (Berry et al., 1997). Desmosome (DMs) are among the first to be affected by this procedure. Regions of the cell membrane where DMs reside invaginate to form intra-cellular vacuoles, and DM cadherins are simultaneously separated from their cytosolic components (Berry et al., 1997). In the second step, the liver is perfused with a collagenase-containing buffer in order to disrupt cellular-extracellular matrix (ECM) interactions (Berry et al., 1997). The presence of $\mathrm{Ca}^{2+}$ ions in this second perfusion buffer is a prerequisite for optimal collagenase activity. At this stage, most of the tight junctions and gap junctions are still present. In order to disrupt them, the digested liver has to be further dispersed mechanically using a spatula (Berry et al., 1997). Finally, connective tissue is removed by filtering, and subsequent centrifugation separates hepatocytes from both dead hepatocytes and non-parenchymal cells (Berry et al., 1997). Finally, immunohistochemistry (Petersen et al., 2003) and Western blotting are used to identify the isolated hepatocyte marker proteins cytokeratin-18 (CK-18) and albumin (ALB) (Shimano et al., 2003 ) in order to improve its purity and activity. 


\section{MATERIAL AND METHODS}

\section{Materials}

Collagenase type IV (0.18 U/mg protein), fetal calf serum, dextromethorphan, verapamil, and p-nitro-phenyl sulfate potassium salt were obtained from Sigma-Aldrich (Taufkirchen, Germany). Percoll was purchased from Biochrom(Berlin, Germany). Dulbecco's modified Eagle's medium (DMEM), 10X Hank's balanced salt solution with $\mathrm{Ca}^{2+}$ and $\mathrm{Mg}^{2+}$ (HBSS), $1 \mathrm{X}$ HBSS with $\mathrm{Ca}^{2+}$ and $\mathrm{Mg}^{2+}$, and uridine 5'-diphospho-glucuronosyltransferase (UDPGA) were obtained from Gibco BRL (Paisley, Scotland or Eggenstein, Germany). Midazolam solution was purchased from Merckle GmbH (Blaubeuren, Germany). Dextrorphan, 3-methoxymorphinan hydrochloride, 1-hydroxymidazolam, 4-hydroxymidazolam, and hydroxytolbutamide were all obtained from Ultrafine Chemicals Ltd. (Manchester, England). The reduced form of dihydronicotinamide adenine dinucleotide phosphate (NADPH), 4-nitrophenyl- $\beta$-D-glucopyranosidurone acid, and all other chemicals were purchased from Merck KGaA (Darmstadt, Germany). Observations were made with a JEOL JSM-5200 scanning electron microscope (SEM; Tokyo, Japan).

\section{Hepatocyte isolation}

Hepatocyte isolation was performed between 800 and $1000 \mathrm{~h}$. The bovine abdomen was scrubbed with $75 \%$ alcohol, and the abdomen was opened to expose the liver portal vein. Intubation, ligation, and perfusion of D-Hank's liquid to the inferior vena cava was conducted at $37^{\circ} \mathrm{C}$ at a flow rate of $10-20 \mathrm{~mL} / \mathrm{min}$ until red spots at the liver surface disappeared. Then, the inferior vena cava was immediately cut until the liver surface appeared yellow. The inferior vena cava was clamped and $0.05 \%$ collagenase was perfused at $1-2 \mathrm{~mL} / \mathrm{min}$ to the liver bulge. After $4 \mathrm{~min}$, phosphate-buffered saline (PBS) was perfused at $4^{\circ} \mathrm{C}$. Finally, glass needles were used to split the pieces of liver tissue gently to allow for cell dispersion. The collected cell suspension was filtered through a 400-mesh nylon web. Hepatocytes were washed three times with PBS at $4^{\circ} \mathrm{C}$, and the cell suspension was paved on $60 \%$ Percoll. First, cells were centrifuged at $4^{\circ} \mathrm{C}$ for $15 \mathrm{~min}$ at $200 \mathrm{rpm}$. The precipitate was collected, which was then centrifuged at $4^{\circ} \mathrm{C}$ for $4 \mathrm{~min}$ at $800 \mathrm{rpm}$. Finally, a few hepatocytes were selected by Trypan blue staining, and their morphology and activity was observed under microscope.

All procedures were approved by the Animal Ethics Committee.

\section{Hepatocyte culture}

Hepatocytes were seeded on 9.6- $\mathrm{cm}^{2}$ Petri dishes with a concentration of $1.5 \times 10^{6}$ cells $/ 3.0 \mathrm{~mL}$ culture medium $\left(1.56 \times 10^{5} \mathrm{cells} / \mathrm{cm}^{2}\right)$. Cells were incubated at $37^{\circ} \mathrm{C}$ in a humidified atmosphere of $5 \% \mathrm{CO}_{2}$ for $2 \mathrm{~h}$, allowing cell attachment to plates. The medium was then changed to fresh medium supplemented with $10 \%$ fetal calf serum. Hepatocytes were incubated at different times and the medium was changed every 2 days.

\section{SEM examination}

The morphology and attachment properties of the hepatocytes were determined on 
the third day of the culture by SEM. For this purpose, cells were fixed with $2.5 \%$ glutaraldehyde in $0.1 \mathrm{M}$ cacodylate buffer, $\mathrm{pH} 7.2$, for $30 \mathrm{~min}, 7 \%$ sucrose in $0.1 \mathrm{M}$ cacodylate buffer, and $1 \%$ osmium tetraoxide in $0.1 \mathrm{M}$ cacodylate buffer. Samples were dehydrated in a graded ethanol series $(30,40,50,60,75 \%)$, desiccated for $10 \mathrm{~min}$ in hexamethyldisilazane, followed by air-drying for $20 \mathrm{~min}$, and incubated in a desiccator with phosphorus pentaoxide overnight. Finally, samples were coated with a thin layer of gold by ion sputtering and were then examined using a JEOL JSM-5200 SEM.

\section{Hepatocyte identification}

\section{Immunohistochemistry}

A few good growth hepatocytes were selected and seeded on 24-well plates in culture medium, allowing cell attachment to 24 plates. The medium was then discarded, and cells were washed twice in $1 \mathrm{~mL}$ PBS at $4^{\circ} \mathrm{C}$ for 10 min each time. Cells were fixed in $1 \mathrm{~mL}$ methanol at $4^{\circ} \mathrm{C}$, incubated for $20 \mathrm{~min}$ at $37^{\circ} \mathrm{C}$, washed three times in PBS at $4^{\circ} \mathrm{C}$ for 5 min each time, transferred to $1 \mathrm{~mL}$ PBS with $0.1 \%$ Triton X-100 (PBS-T) at $4^{\circ} \mathrm{C}$, and incubated for 10 min. The PBS-T liquid was then discarded, cells were washed in PBS at $25^{\circ} \mathrm{C}$ for $5 \mathrm{~min}$, immersed in $1 \mathrm{~mL}$ PBS with $4 \%$ bovine serum albumin (BSA) (PBS-B), incubated at $37^{\circ} \mathrm{C}$ for $30 \mathrm{~min}$, and antibody (rabbit polyclonal to albumin, 1:300 dilution) was added and the culture was incubated for a further $2 \mathrm{~h}$ at $37^{\circ} \mathrm{C}$. The antibody was removed, the culture was washed at $4^{\circ} \mathrm{C}$ in PBS for $5 \mathrm{~min}$, the secondary antibody was added and the culture was incubated for a further $2 \mathrm{~h}$ at $37^{\circ} \mathrm{C}$, and then washed three times in PBS at $4^{\circ} \mathrm{C}$ for 5 min each time. Cells were mounted for fluorescence microscopy observation and photographed; green fluorescence indicated positive signals.

\section{Western blotting}

\section{Protein sample preparation and protein concentration measurement}

To $5 \times 10^{6}$ isolated hepatocytes, $500 \mu \mathrm{L} 4{ }^{\circ} \mathrm{C}$ lysate was added and incubated at $0^{\circ} \mathrm{C}$ for $30 \mathrm{~min}$. The solution was centrifuged at $12,000 \mathrm{rpm}$ at $4^{\circ} \mathrm{C}$ for $5 \mathrm{~min}$ to obtain the total protein solute. Next, a $20-\mu \mathrm{L}$ protein sample was placed in a cellulose acetate membrane, dried at $37^{\circ} \mathrm{C}$, and dyed with amido black for $5 \mathrm{~min}$. Bleaching occurred by liquid decolorization oscillation three times, for 5 min each time. The membrane was completely dissolved in DMSO, and sample absorbance was read at a $630-\mathrm{nm}$ wavelength. Each sample was replicated three times.

\section{Sodium dodecyl sulfate-polyacrylamide gel electrophoresis (SDS-PAGE)}

The 10\% separation gel was slowly poured into the glue groove (Laemmli, 1970). Water and saturated n-butyl alcohol was then added and the gel was incubated at room temperature for $2 \mathrm{~h}$. The upper aqueous phase was discarded, and the gel was rinsed three times in double-distilled water. The comb was inserted, $6 \%$ concentrated gel was added, and incubated at room temperature for $20 \mathrm{~min}$. The comb was removed, samples were rinsed three times in 
double-distilled water, and $20 \mu \mathrm{g}$ electrophoresis samples were loaded in the sample groove. The initial electrophoresis voltage was $80 \mathrm{~V}$, when indicators moved into the separation gel, the voltage was increased to $120 \mathrm{~V}$, and electrophoresis continued until the indicator reached the end of the gel.

\section{Transfer film}

The gel plate was removed, transferred to a Petri dish, transfer buffer was added, and incubated for $30 \mathrm{~min}$. At the same time, the nitrocellulose membrane was immersed in transfer buffer and incubated for $20 \mathrm{~min}$. The plate and nitrocellulose membrane were assembled into a "sandwich" structure and placed in the electrophoresis groove. Electrophoresis was run at $4^{\circ} \mathrm{C}$ for $12 \mathrm{~h}$ under an electric current of $150 \mathrm{~mA}$.

\section{Immunization coloration}

After electrophoretic transfer, the nitrocellulose membrane was rinsed with PBS/ Tween 20 three times for 5 min each time, immersed in 2\% BSA, incubated for 30 min, and rinsed another three times in PBS/Tween 20 for 5 min each time. Finally, the membrane was combined with V(ALB-Anti): $\mathrm{V}$ (PBS) (1:1000) for $1 \mathrm{~h}$, and then with V(ck-18-Anti): $\mathrm{V}(\mathrm{PBS})$ (1:500) for $30 \mathrm{~min}$. Membranes were rinsed in PBS/Tween20 three times for 5 min each, incubated in the dark at $37^{\circ} \mathrm{C}$ for 25 min until reaching the color finish using TE buffer solution (Towbin et al., 1979).

\section{Positive band analysis}

Positive band analysis was accomplished using BenQ scanner scan coloration bands, with the Band Scan5.0 software, to analyze gray color bands based on the indicated ALB quantity (Huang and Wang, 2006).

\section{RESULTS}

In this study, hepatocyte isolation was performed using a simple enzymatic method based on the use of collagenase. Percoll solution was used to increase cell density and to obtain a homogeneous hepatocyte suspension. The polymers used in this study were all UV sterilized. When the cell culture medium was added to substrates, the $\mathrm{pH}$ decreased markedly in wells coated with chitosan, and decreased slightly in wells coated with collagen. In order to increase the $\mathrm{pH}$, these wells were washed with $50 \mathrm{~mL} 8.5 \% \mathrm{NaHCO}_{3}$. Hepatocyte culture systems were designed as single layers of gelatin, collagen, or chitosan polymers. Additionally, a mixture of gelatin-cell suspension and sandwich configurations were examined as hepatocyte culture systems.

Cell culture studies were carried out with an initial concentration of $10^{6}$ cells $/ \mathrm{mL}$. On the second day of culture, individual cells began to form aggregates. Hepatocytes cultured on chitosan and collagen substrates proliferated quickly and were predominant in terms of aggregate formation at the beginning of the culture. However, damage on hepatocyte membranes was observed in chitosan-coated wells over the following days of culture. Gelatin showed 
improved cellular viability for hepatocytes. After 2 days of culture, cells on gelatin substrates began to lose their membrane borders.

The adhesion and ECM secretion of the cells were examined by SEM. Results indicated that the hepatocytes were of large size, had strong refraction, clear cytoplasm, and large and round nuclei; some cells were binuclear (Figure 1A-D).

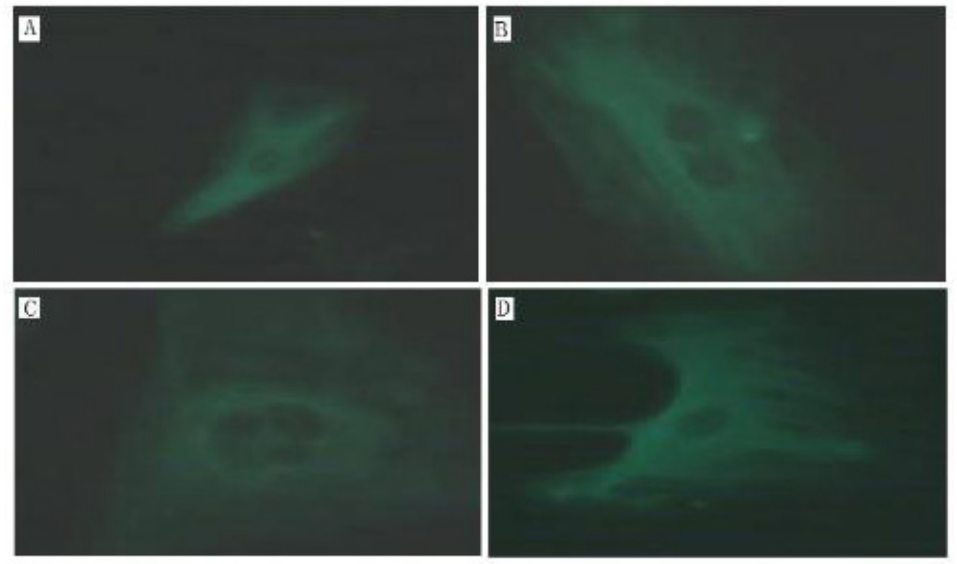

Figure 1. Primary hepatocyte cultures. A. Hepatocyte cell. B. Splitting into 2 hepatocytes. C. Splitting into 3 hepatocytes. D. Just a well-differentiated hepatocyte.

ALB and CK-18 are commonly used marker proteins of hepatocytes. Therefore, they serve in hepatocellular identification. The results showed that more than $98 \%$ of the cytoplasm contained ALB and CK-18 (Figures 2 and 3). Western blot analysis revealed the same result (Figure 4).

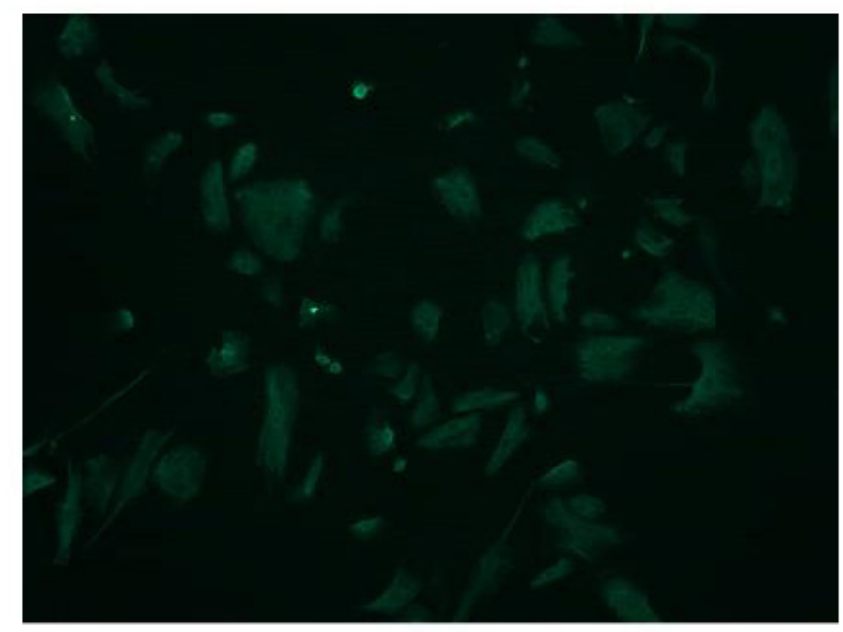

Figure 2. Albumin immunofluorescence identification. 


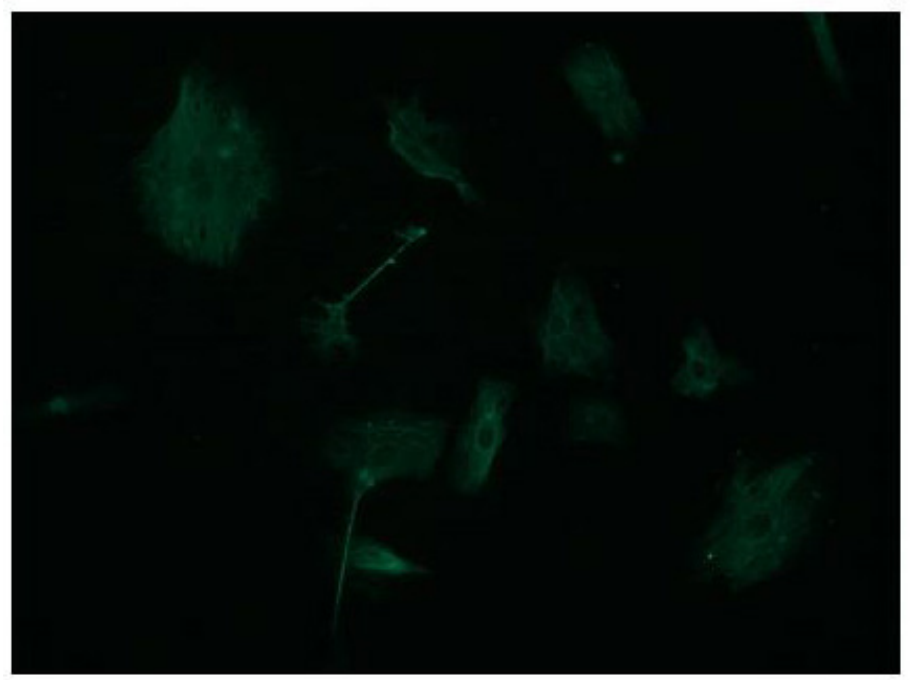

Figure 3. Cytokeratin-18 immunofluorescence identification.
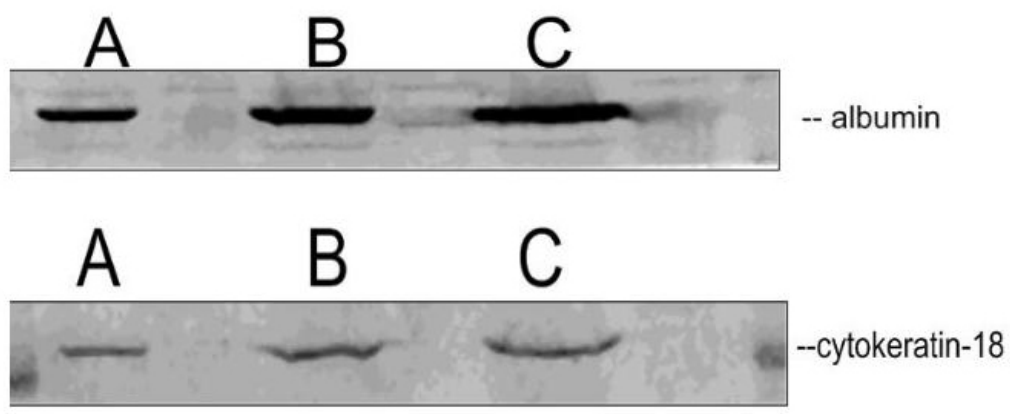

Figure 4. Time course of albumin and cytokeratin-18 proteins in perfused primary hepatocytes analyzed by Western blot. Lanes $A, B, C=$ hepatocyte cells with samples of 20,50 and $100 \mu \mathrm{g}$, respectively.

\section{DISCUSSION}

Some methods have been proposed for culturing primary hepatocytes, but these methods often result in serious damage to cells, and the cell survival rate is relatively low $(\leq 50 \%)$. The present study aimed to prepare high-purity primary hepatocyte cultures. Hepatocyte isolation was achieved by collagenase solution and perfusion. Percoll solution was used for further purification of the cells (Puviani et al., 1998). The cell damage was much lower, and a high cell yield was obtained compared to other methods. Hepatocyte isolation depends on the proficiency of the experimenter, operability, and reagent product quality. Therefore, some studies have reported great changes in hepatocyte survival rates. In addition, if dead hepatocytes are not removed immediately, they will release large amounts of DNA, lactate dehydrogenase, and intracellular antigens, thus further reducing cell viability. Using collagenase digestion, perfu- 
sion, and $60 \%$ Percoll centrifugation to separate and purify hepatocytes, we here achieved a hepatocyte survival rate of more than $95 \%$.

The isolated hepatocytes showed clear and bright contours with and high activity, based on observations with Trypan blue staining. ALB and CK-18 immunohistochemistry and Western blot analysis confirmed that the purity of the isolated hepatocytes was over $96 \%$. Furthermore, the use of $60 \%$ Percoll centrifugation to separate and purify hepatocytes to ensure that the dead cells and their fragments were separated from the liquid layer effectively improved the cells' activity. In conclusion, we demonstrated that the dispersion cell method is a better method for the separation and purification of hepatocytes: the separation reagent ratio is reasonable, and a wide range of Percoll concentrations can effectively remove the impurities of dead cells and cell fragments.

Hepatocyte morphology, polarity, and liver-specific functions were previously shown to be maintained using the collagen sandwich method. Therefore, in the present study, the method proposed was used to obtain the sandwich configuration.

In vitro studies have demonstrated that it is possible to obtain hepatocyte populations using our method. This method is therefore useful for establishing highly reproducible hepatocyte cultures, which have great potential for toxicity studies.

\section{ACKNOWLEDGMENTS}

Research supported by the Project of the National Major Basic Dairy Research "973" Plan (\#2011CB100802) and by the Ministry of Agriculture (grant \#2011-G35).

\section{REFERENCES}

Azuma H, Hirose T, Fujii H, Oe S, et al. (2003). Enrichment of hepatic progenitor cells from adult mouse liver. Hepatology 37: 1385-1394.

Battle T and Stacey G (2001). Cell culture models for hepato-toxicology. Cell Biol. Toxicol. 17: 287-289.

Berry MN, Grivell AR, Grivell MB and Phillips JW (1997). Isolated hepatocytes - past, present and future. Cell Biol. Toxicol. 13: 223-233.

Bordoni V, Alonzi T, Agrati C, Poccia F, et al. (2004). Murine hepatocyte cell lines promote expansion and differentiation of NK cells from stem cell precursors. Hepatology 39: 1508-1516.

Crosby HA, Kelly DA and Strain AJ (2001). Human hepatic stem-like cells isolated using c-kit or CD34 can differentiate into biliary epithelium. Gastroenterology 120: 534-544.

Guguen-Guillouzo C (2002). Isolation and Culture of Animal and Human Hepatocytes. In: Culture of Epithelial Cells (Freshney RI and Freshney MG, eds.). Wiley-Liss, New York, 337-379.

Hengstler JG, Van der Burg B, Steinberg P and Oesch F (1999). Interspecies differences in cancer susceptibility and toxicity. Drug Metab. Rev. 31: 917-970.

Hengstler JG, Ringel M, Biefang K, Hammel S, et al. (2000a). Cultures with cryopreserved hepatocytes: applicability for studies of enzyme induction. Chem. Biol. Interact. 125: 51-73.

Hengstler JG, Utesch D, Steinberg P, Platt KL, et al. (2000b). Cryopreserved primary hepatocytes as a constantly available in vitro model for the evaluation of human and animal drug metabolism and enzyme induction. Drug Metab. Rev. 32: $81-118$.

Hengstler JG, Bogdanffy MS, Bolt HM and Oesch F (2003). Challenging dogma: thresholds for genotoxic carcinogens? The case of vinyl acetate. Annu. Rev. Pharmacol. Toxicol. 43: 485-520.

Huang H and Wang NC (2006). ShRNA of PCN aeukaryotic expression vector construction and cervix cancer cells intervention research. Tumor Res. 33: 662-664.

Kravchenko L, Petrenko A, Shanina I and Fuller B (2002). A simple non-enzymatic method for the isolation of high yields of functional rat hepatocytes. Cell Biol. Int. 26: 1003-1006. 
Laemmli UK (1970). Cleavage of structural proteins during the assembly of the head of bacteriophage T4. Nature 227: 680-685.

Li AP, Gorycki PD, Hengstler JG, Kedderis GL, et al. (1999). Present status of the application of cryopreserved hepatocytes in the evaluation of xenobiotics: consensus of an international expert panel. Chem. Biol. Interact. 121: 117-123.

Li K, Qu X, Wang Y, Tang Y, et al. (2005). Improved performance of primary rat hepatocytes on blended natural polymers. J. Biomed. Mater. Res. A 75: 268-274.

Morsiani E, Pazzi P, Puviani AC, Brogli M, et al. (2002). Early experiences with a porcine hepatocyte-based bioartificial liver in acute hepatic failure patients. Int. J. Artif. Organs 25: 192-202.

Nagaki M, Miki K, Kim YI, Ishiyama H, et al. (2001). Development and characterization of a hybrid bioartificial liver using primary hepatocytes entrapped in a basement membrane matrix. Dig. Dis. Sci. 46: 1046-1056.

Osterod M, Larsen E, Le Page F, Hengstler JG, et al. (2002). A global DNA repair mechanism involving the Cockayne syndrome B (CSB) gene product can prevent the in vivo accumulation of endogenous oxidative DNA base damage. Oncogene 21: 8232-8239.

Park KH and Song SC (2006). Morphology of spheroidal hepatocytes within injectable, biodegradable, and thermosensitive poly (organophosphazene) hydrogel as cell delivery vehicle. J. Biosci. Bioeng. 101: 238-242.

Petersen BE, Grossbard B, Hatch H, Pi L, et al. (2003). Mouse A6-positive hepatic oval cells also express several hematopoietic stem cell markers. Hepatology 37: 632-640.

Puviani AC, Ottolenghi C, Tassinari B, Pazzi P, et al. (1998). An update on high-yield hepatocyte isolation methods and on the potential clinical use of isolated liver cells. Comp. Biochem. Physiol. A Mol. Integr. Physiol. 121: 99-109.

Ringel M, Oesch F, Gerl M, Klebach M, et al. (2002). Permissive and suppressive effects of dexamethasone on enzyme induction in hepatocyte co-cultures. Xenobiotica 32: 653-666.

Shen C, Zhang G, Qiu H and Meng Q (2006). Acetaminophen-induced hepatotoxicity of gel entrapped rat hepatocytes in hollow fibers. Chem. Biol. Interact. 162: 53-61.

Shimano K, Satake M, Okaya A, Kitanaka J, et al. (2003). Hepatic oval cells have the side population phenotype defined by expression of ATP-binding cassette transporter ABCG2/BCRP1. Am. J. Pathol. 163: 3-9.

Towbin H, Staehelin T and Gordon J (1979). Electrophoretic transfer of proteins from polyacrylamide gels to nitrocellulose sheets: procedure and some applications. Proc. Natl. Acad. Sci. U. S. A. 76: 4350-4354.

Tsuchiya A, Heike T, Fujino H, Shiota M, et al. (2005). Long-term extensive expansion of mouse hepatic stem/progenitor cells in a novel serum-free culture system. Gastroenterology 128: 2089-2104. 